\title{
Comparação entre as análises integrada e paramétrica na suscetibilidade a escorregamentos no entorno de dutos: faixa de dutos Orbel, Estado do Rio de Janeiro
}

\author{
Camila A. Coelho da SILVA ${ }^{1 *} \&$ Paulina Setti RIEDEL ${ }^{2}$
}

${ }^{1}$ Programa de Pós-graduação em Geociências e Meio Ambiente, Universidade Estadual Paulista. Av. 24 A, 1515, Bela Vista, CEP 13506-900, Rio Claro, SP, Brasil (E-mail: camila_acoelho@yahoo.com.br).

${ }^{2}$ Departamento de Geologia Aplicada, Instituto de Geociências e Ciências Exatas. Universidade Estadual Paulista. Av. 24 A, 1515, Bela Vista, CEP 13506-900, Rio Claro, SP, Brasil (E-mail: psriedel@rc.unesp.br).

Silva, C.A.C da \& Riedel, P.S. 2018. Comparação entre as análises integrada e paramétrica na suscetibilidade a escorregamentos no entorno de dutos: faixa de dutos Orbel, Estado do Rio de Janeiro. Pesquisas em Geociências, 45 : e0580.

DOI: https://doi.org/10.22456/1807-9806.85636

Resumo. Este trabalho teve como objetivo comparar a Abordagem Paramétrica, realizada por meio da sobreposição com ponderação de mapas, com a Integrada/Fisiográfica, ancorada na fotointerpretação de produtos de sensoriamento remoto, na obtenção da suscetibilidade a escorregamentos com a utilização de imagens de alta resolução. A área de estudo possui 108,6 km² e corresponde a um trecho da faixa de dutos ORBEL, Estado do Rio de Janeiro. As etapas de trabalho envolveram: levantamento bibliográfico; confecção de mapas auxiliares através do MDE; o Mapa de Inventário a Escorregamentos, onde foram identificadas 165 cicatrizes; elaboração do Mapa de Suscetibilidade a Escorregamento - Compartimentação Fisiográfica a partir da fotointerpretação das imagens orbitais, e do Mapa de Suscetibilidade a Escorregamento - Método AHP (Processo de Análise Hierárquico) pelo cruzamento com ponderação dos mapas correspondentes aos fatores condicionantes do processo. A comparação dos mapas de suscetibilidade, ambos com 4 classes, foi realizada por tabulação cruzada e também de forma descritiva. Concluiu-se que a Abordagem Paramétrica mostrou-se mais detalhada e consistente, com maior número de cicatrizes nas classes de Muito Alta e Alta suscetibilidade. A análise integrada, embora mais geral, foi suficiente para a produção do mapa de suscetibilidade e pode se constituir numa alternativa para obras lineares de grande extensão, por não requerer mapas em escalas compatíveis, o que se configura como uma dificuldade no país. As duas abordagens podem ser complementares, com a Abordagem Paramétrica somente em trechos onde o detalhamento seja necessário.

Palavras-chave. Abordagem Integrada ou Fisiográfica, Abordagem Paramétrica, Imagem GeoEye, escorregamentos.

Abstract. COMPARISON BETWEEN THE INTEGRATED AND PARAMETRIC ANALYZES IN THE STUDY OF LANDSLIDES SUCEPTIBILITY IN PIPILENES AROUND: ORBEL PIPELINES STRIP, RIO DE JANEIRO STATE. This research aimed the comparison between the Parametric Approach, conducted through the overlay of weighted maps, and the Integrated one, anchored in the photo-interpretation of remote sensing images, to obtain the susceptibility to landslides using high resolution images. The study area has $108.6 \mathrm{~km}^{2}$, is a stretch of the ORBEL pipelines strip in Rio de Janeiro State. The research steps involved: bibliographic data; production of the auxiliary maps: DEM; the Landslide Inventory Map, with a total of 165 identified features, generation of the Landslide Susceptibility Map - Physiographic Compartmentalization from photo-interpretation of satellite; and the Landslide Susceptibility Map - AHP (Analytic Hierarchy Process) obtained by the overlay of all maps in terms of weighted overlay methods. The comparison between the two susceptibility maps, with 4 classes, was carried out using cross tabulation and also a descriptive analysis. It was concluded that the Parametric Approach was more detailed and consistent, with a greater number of scars in the Very High and High Susceptibility classes. The integrated analysis, although more general, was sufficient for the production of the susceptibility map and can be an alternative for linear works of great extension, for not requiring maps in compatible scales, which is configured as a difficulty in the country. The two approaches may be complementary, with the Parametric Approach only in sections where detailing is necessary. Keywords. Integrated or Physiographic Approach, Parametric Approach, GeoEye Image, landslides. 


\section{Introdução}

Desde o final do século XX, mais precisamente na década de 80 , observou-se uma crescente preocupação com o meio ambiente em todo o mundo, ocasionando um aumento gradativo dos estudos voltados à temática ambiental. Uma das formas de se estudar o meio físico é através da avaliação de terrenos, com grande contribuição nos estudos das potencialidades e limitações do meio físico e da sua suscetibilidade a processos naturais.

Os movimentos gravitacionais de massa se constituem num relevante processo do meio físico, cuja suscetibilidade pode ser abordada por meio de diferentes técnicas de avaliação de terrenos. Os movimentos de massa ocorrem sucessivamente em diferentes escalas de tempo e espaço, contribuindo na evolução natural das encostas. Os escorregamentos representam os principais processos desse quadro evolutivo ocorrendo naturalmente nas médias e altas encostas das serras, mesmo em vertentes totalmente isentas de qualquer ação antrópica (Wolle \& Carvalho, 1989) e são geralmente decorrentes de eventos pluviométricos intensos (Guidicini \& Nieble, 1984; IPT, 1988).

A determinação da suscetibilidade à ocorrência de escorregamentos permite que sejam sintetizadas as informações sobre o meio físico, discriminando áreas mais ou menos propensas ao desenvolvimento do processo. Essas informações fornecem importantes subsídios aos administradores, planejadores e técnicos em geral, que atuam nas questões relativas ao planejamento territorial e ambiental.

Há duas abordagens metodológicas distintas de avaliação de terrenos que podem ser utilizadas no mapeamento da suscetibilidade ao escorregamento: o Sistema de Classificação Paramétrica (Parametric Approach) e o Sistema de Classificação de Paisagem ou Fisiográfica (Landscape or Physiographic Approach), conforme citado por diversos autores, tais como Mabbut (1968), Mitchell (1973) e Bennett \& Doyle (1997).

A Abordagem Paramétrica, bastante utilizada, é muito bem sucedida quando aplicada com finalidade de quantificação. Este método se baseia na sobreposição e cruzamento, muitas vezes com atribuição de pesos, de vários mapas temáticos, que representam condicionantes do processo, para a definição das zonas com as mesmas características. A sobreposição era incialmente feita de forma manual (Buringh, 1960; Mabbutt, 1968 apud Verstappen, 1983) e, com o advento dos Sistemas de Informação Geográfica teve sua aplicação disseminada em diferentes áreas das Geociências, inclusive na análise de suscetibilidade ao escorregamento (Barredo et al., 2000; Fernandes et al., 2001; Ayalew et al., 2004; Araujo, 2004; Lee, 2005; Komac, 2006; Gorsevski et al., 2006; Ferreira et al, 2008; Yalcin, 2008; Akgun \& Türk, 2010; Ahmed, 2015; Feizizadeh \& Blaschke, 2013; Silveira et al., 2014).

Na Abordagem Paramétrica, os mapas temáticos a serem cruzados apresentam os dados préclassificados, muitas vezes de forma não adequada à análise pretendida e os contatos gerados são por vezes discutíveis quanto aos critérios adotados e podem necessitar de ajustes para se adequar à realidade do terreno (Diniz, 2012) e à escala de trabalho. Porém, esta abordagem tem como vantagem permitir automação das operações de cruzamentos das informações, com a utilização dos Sistemas de Informação Geográfica. Além disso, torna possível a padronização das formas de gerenciamento dos dados, desde sua aquisição até a análise final. A principal desvantagem desta técnica é exigir mapas temáticos em escalas compatíveis entre si e a possível demora no processo de entrada e tratamento dos dados, o que é especialmente relevante quando áreas extensas são consideradas (Aleotti \& Chowdhury, 1999).

A Abordagem Integrada ou Fisiográfica consiste na compartimentação da área de estudo em unidades fisiográficas ou unidades do terreno, e teve sua origem na década de 50, com CSIRO (Scientific and Industrial Research Organisation), na Austrália (Christian \& Stewart, 1953). 0 método de sistema de classificação de terrenos foi detalhado, posteriormente, por Christian (1958) e Christian 
\& Stewart (1964), que foram responsáveis pela compartimentação baseada na origem geomórfica comum (Tominaga, 2007) e, desde então, diversos autores a utilizaram (Grant, 1970; Mitchell, 1973; Verstappen \& Zuidan, 1975; Grant, 1975a, 1975b; Grant \& Finlayson, 1978; Verstappen, 1983). Apesar da diversidade de abordagens, esta linha metodológica considera que terrenos com aspectos fisiográficos semelhantes, submetidos às mesmas condições tectônicas e climáticas, têm comportamentos semelhantes (Tominaga, 2007).

$\mathrm{Na}$ Abordagem Integrada, as unidades fisiográficas ou de terreno são obtidas por meio das inter-relações entre geologia, geomorfologia e solos, de tal forma que cada unidade representa associação única de litologia, solo e relevo e declividade (Zuquete, 1991 apud Tominaga, 2007; Souza, 1992; Collares, 1994; Zuquete \& Pejon, 1996; Lollo, 1996; Aguiar, 1997; Crepani et al., 2001; Tominaga, 2007; Zaine, 2011). Estas unidades são identificadas e analisadas conjuntamente por meio de técnicas fotointerpretativas, ancoradas nas formas de relevo e drenagem, e classificadas com diferentes objetivos, entre eles a análise da suscetibilidade ao escorregamento, discutida neste trabalho. Para auxiliar na interpretação e delimitação das unidades podem ser utilizados mapas específicos (Diniz, 2012) representados principalmente por mapas geológicos, pedológicos, geomorfológicos, cartas topográficas e modelos digitais de elevação.

Uma das desvantagens da Abordagem Integrada consiste em sua subjetividade no fato de ser dependente da experiência do fotointérprete. Porém, ela pode ser utilizada em variadas escalas e adaptada aos requisitos específicos de cada localidade (Aleotti \& Chowdhury, 1999).

As técnicas de sensoriamento remoto desempenham papel importante nas duas formas de abordagem. Na Abordagem Integrada, no processo de compartimentação do terreno, são delimitadas e caracterizadas as unidades de terreno, por meio do reconhecimento das feições de relevo e drenagem e de seu arranjo espacial para a identificação de unidades homólogas da paisagem e posterior avalia- ção de suas similaridades. Na Abordagem Paramétrica, as imagens de sensoriamento remoto são utilizadas como apoio para a elaboração dos mapas temáticos, que representam os condicionantes do processo, e que são posteriormente cruzados, com ou sem atribuição de pesos, para a obtenção das classes de suscetibilidade.

As abordagens integrada e paramétrica são amplamente utilizadas na bibliografia nacional e internacional, na avaliação de terrenos com diferentes fins, entre eles na obtenção de mapas de suscetibilidade a escorregamento. Tominaga (2007) utilizou e comparou as duas abordagens, no município de Ubatuba (SP), na análise de risco a escorregamentos, porém de forma qualitativa, avaliando a vantagem e desvantagem dos dois métodos e considerando o ensaio para um município. Nesse trabalho, os autores pretendem a comparação entre os mapas obtidos pelas duas abordagens, com o suporte da tabulação cruzada, que permite avaliar o grau de concordância entre as classes de suscetibilidade geradas. Além disto, pretende-se também o subsídio ao monitoramento de dutos, que são obras lineares, com grandes extensões, do que decorrem necessidades e limitações específicas.

A área de estudo localiza-se no município de Duque de Caxias, abrangendo pequena porção também dos municípios de Nova Iguaçu e Belford Roxo, no estado do Rio de Janeiro e é cruzada pela faixa de dutos ORBEL, operada pela Transpetro. A faixa de dutos ORBEL atravessa 27 municípios, sendo 6 municípios no estado do Rio de Janeiro e 21 municípios no estado de Minas Gerais. Com uma extensão aproximada de $363,9 \mathrm{~km}$, estende-se desde o município de Duque de Caxias (RJ) até Betim (MG). A área de estudo corresponde a um trecho de 108,6 $\mathrm{km}^{2}$ desta faixa de dutos e apresenta porções com alta incidência de escorregamentos, principalmente em períodos de alta pluviosidade. 0 trecho selecionado abrange municípios pertencentes à Região Metropolitana do Rio de Janeiro, onde há uma dinâmica socioeconômica acelerada, com relevante parque industrial e um contingente populacional bastante expressivo. 


\section{2 Área, materiais e métodos}

\subsection{Localização da área}

Localizada principalmente no município de Duque de Caxias e em parte dos municípios de Nova Iguaçu e Belford Roxo, na região centro-sul do
Estado do Rio de Janeiro, a área de estudo situa-se próximo à REDUC - Refinaria Duque de Caxias, de onde partem as faixas de dutos ORBEL I e ORBEL II, que atravessam toda área seguindo em direção ao Estado de Minas Gerais. Apresenta aproximadamente $6 \mathrm{~km}$ de largura e 18,1 km de extensão, totalizando 108,6 km² (Fig. 1).

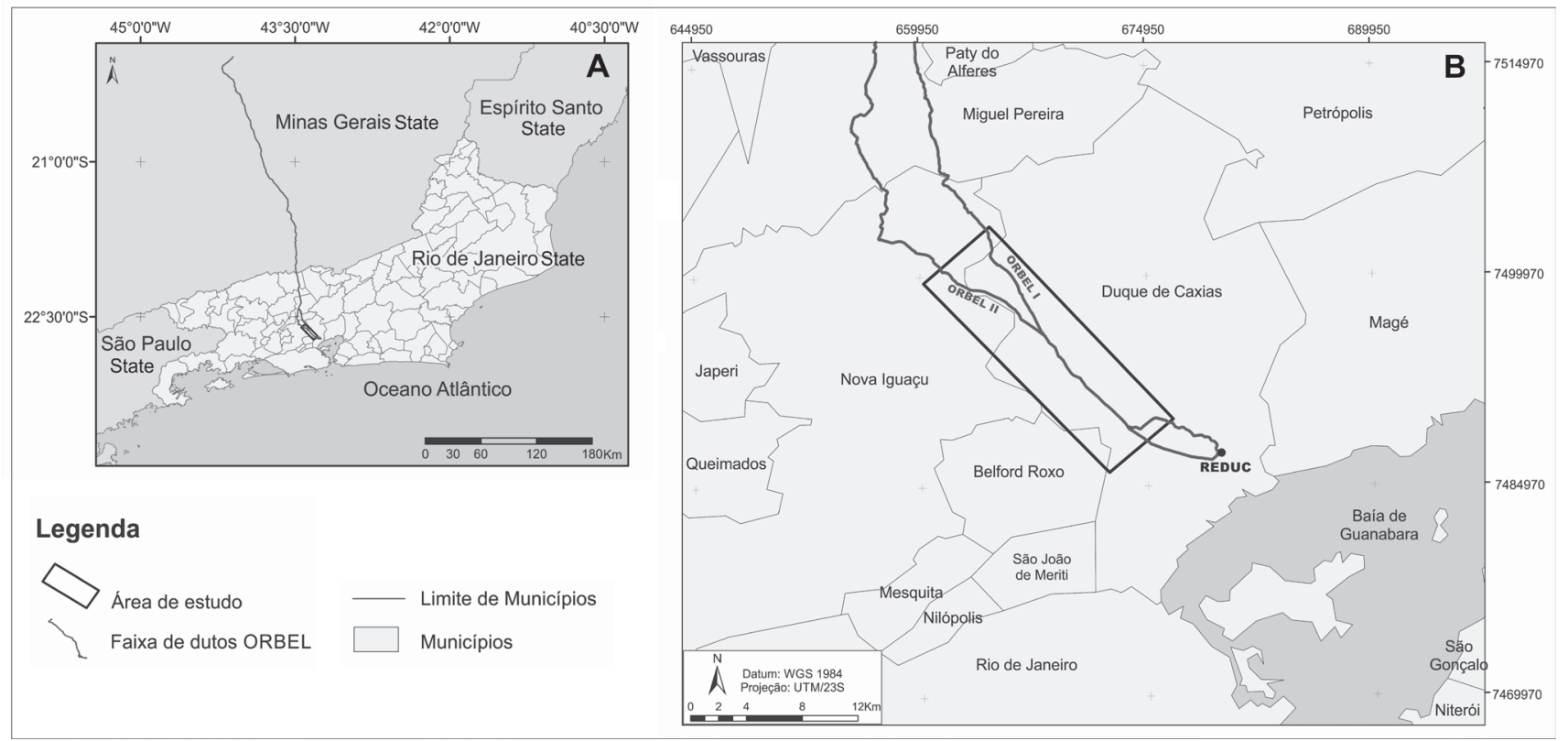

Figura 1. Mapa de localização. A) Localização da Faixa de dutos Orbel desde o Estado de Minas Gerais até o Estado do Rio de Janeiro; B) Área de estudo e municípios os quais abrange no Estado do Rio de Janeiro.

Figure 1. Location map. A) Location of Orbel pipelines strip from the State of Minas Gerais to the State of Rio de Janeiro; B) Area of study and municipalities which covers in the State of Rio de Janeiro.

\subsection{Contexto geológico e geomorfológico}

$\mathrm{Na}$ área de estudo ocorrem quatro unidades litológicas, segundo CPRM (2000). A Unidade Serra dos Órgãos e a Unidade Santo Aleixo, de idade neoproterozoica, constituem-se basicamente por granitoides, sendo a primeira representada por batólito granítico de $140 \mathrm{~km}$ de comprimento e direção NE/SW, envolvido nas bordas nordeste e sul pela Unidade Santo Aleixo. A Suíte do Tinguá, de idade cretácica, de origem alcalina, restringese a pequena ocorrência, no extremo noroeste da área de estudo. Os Depósitos Aluvionares pertencentes ao Cenozoico/Quaternário constituem-se por depósitos fluviais areno-siltico-argilosos com camadas de cascalheiras associadas a depósitos de tálus e sedimentos lacustrinos retrabalhados, que ocorrem nas regiões mais baixas da região.

Estão presentes cinco diferentes unidades de relevo, cujas descrições foram obtidas de CPRM (2000). As Colinas Isoladas são constituídas de formas de relevo residuais, que possuem vertentes convexas e topos arredondados ou alongados, com sedimentação de colúvios e não ultrapassam os 100 m de amplitude. O Domínio de Colinas Dissecadas, Morrotes e Morros Baixos é classificado como relevo de degradação em planaltos dissecados ou superfícies aplainadas e apresentam amplitudes entre 100 e 200 m. As colinas dissecadas têm vertentes convexo-côncavas e topos arredondados e/ou alongados, os morrotes e morros dissecados têm vertentes retilíneas e côncavas e topos aguçados ou alinhados, com sedimentação de colúvios e alúvios.

As Escarpas Serranas constituem um relevo montanhoso e extremamente acidentado. Essa unidade de relevo é classificada por relevos de degradação em áreas montanhosas, cujas vertentes são retilíneas a côncavas, escarpadas e com topos de cristas alinhadas, as amplitudes são superiores a $500 \mathrm{~m}$ e de gradientes muito elevados, com com ocorrência de colúvios e depósitos de tálus, solos 
rasos e afloramento de rocha.

As Planícies Colúvio-Alúvio-Marinhas apresentam relevo de agradação litorânea, constituído por terrenos argilo-arenosos das baixadas. São superfícies subhorizontais, de gradientes extremamente suaves e convergentes à linha de costa, de interface com os sistemas deposicionais continentais (processos fluviais e de encosta como tálus e colúvio) e marinhos. Os terrenos são mal drenados com padrão de canais meandrantes e divagantes. Estão presentes superfícies de aplainamento e pequenas colinas ajustadas ao nível de base das baixadas.

\subsection{Materiais}

Para a elaboração do presente trabalho foram utilizados os seguintes materiais: imagens do sistema sensor GeoEye-1, com resolução espacial de 0,5 metros, referente aos meses de Novembro/2009, Janeiro/2010, Março/2010 e Julho/2010. Material cartográfico, em formato Digital Raster: Mapa de Unidades Geológicas do Estado do Rio de Janeiro, escala 1:400.000 (CPRM, 2000); Mapa de Unidades Geomorfológicas do Estado do Rio de Janeiro, escala 1:400.000 (CPRM, 2000); Mapa de Unidades do Relevo do Estado do Rio de Janeiro, escala 1:400.000 (CPRM, 2000); Mapa de Sistemas do Relevo do Estado do Rio de Janeiro, escala 1:250.000 (CPRM, 2000); Cartas Topográficas da FUNDREM - Fundação para o Desenvolvimento da Região Metropolitana do Rio de Janeiro, escalas 1:10.000, curvas de nível com $5 \mathrm{~m}$ de equidistância, do ano de 1975. Material cartográfico em formato vetorial: Traçado Faixa de Dutos (Rio - Belo Horizonte), escala 1:30.000, adquirido pelo Projeto (Petrobras Transporte S.A.). Material em formato PDF: Mapa de Geologia e de Geomorfologia do Município de Duque de Caxias, escala 1:250.000 (NIMA, 2009); Mapa de Geologia e de Geomorfologia do Município de Nova Iguaçu, escala 1:250.000 (NIMA, 2010). Os softwares Envi 4.7 (RSI, 2009) e ArcGIS 10.1 (ESRI, 2010) foram utilizados, respectivamente, para o tratamento de imagens e integração das informações.

\subsection{Métodos e etapas de trabalho}

A primeira etapa de trabalho constituiu do levantamento bibliográfico sobre a área de estudo e sobre as técnicas das análises paramétrica e integrada. Também foi realizado o pré-processamento das imagens que consistiu inicialmente na correção geométrica chamada de ortorretificação e/ou registro de imagens, realizada no software Envi 4.7 (RSI, 2009). Para isso foram utilizadas as cartas topográficas da FUNDREM como base cartográfica, que permitiu a identificação clara dos pontos de controle escolhidos tanto na base quanto na imagem a ser ortorretificada. Os pontos escolhidos localizam-se ao nível do solo, o que diminuiu as distorções inerentes ao ângulo de aquisição da imagem, e foram distribuídos homogeneamente por toda a imagem. Outro procedimento realizado previamente nas imagens foi a fusão pela técnica IHS, realizada no software Envi 4.7, o que permitiu que fosse reunido, em um único produto, a melhor resolução espacial inerente à banda pancromática, com a resolução espectral das bandas multiespectrais.

A segunda etapa de trabalho foi a adequação das escalas dos mapas, uma vez que as escalas dos mapas adquiridos não eram compatíveis com a escala pretendida no trabalho (1:50.000). Para tal, utilizou-se como âncora a imagem GeoEye de Julho de 2010, tanto a multiespectral, com composição colorida das bandas $\operatorname{RGB}(3,2,1)$, quanto a pancromática, uma vez que permitem uma melhor visualização das feições de relevo. Os critérios adotados para os ajustes foram fotointerpretativos: textura, declividade, relações de altitudes, cor, forma e extensão dos topos.

Nesta etapa também foi gerado o Modelo Digital de Elevação (MDE), que é uma forma de representação matemática da topografia, que possibilitou a elaboração dos mapas de declividade, de hipsometria e de formas de vertentes ou curvatura vertical. O Mapa Hipsométrico possui intervalos de altitudes de 40 metros e divididos em oito classes. O Mapa de Declividade foi gerado a partir do MDE utilizando-se a ferramenta Slope, no ArcGis 10.1. Para definição dos intervalos da declividade foram utilizadas as adaptações dos trabalhos de De Biase (1970), Lepsch et al. (1991) e Ross (1995) sugeridas por Amaral (2014), com os intervalos de: 0 a 5\%, 5 a 12\%, 12 a 30\% e maiores que $30 \%$. 0 Mapa de Formas de Vertentes foi obtido a 
partir da ferramenta Curvature do software ArcGis 10.1. Dessa forma, foram destacadas as formas de vertentes côncava, retilíneas e convexas da área. Segundo Valeriano (2008), a curvatura vertical de vertentes possui alto poder de identificação de unidades homogêneas do relevo, por ser um fator relacionado às características do substrato e aos processos de formação do relevo.

Outro produto auxiliar gerado nesta etapa foi o Mapa de Inventário de Escorregamentos, este foi organizado com o intuito de representar e localizar as ocorrências de escorregamentos na área de estudo, para a calibração dos mapas de suscetibilidade, segundo Lopes et al. (2007). As feições equivalentes às cicatrizes de escorregamentos foram identificadas e extraídas na imagem GeoEye de Janeiro/2010, imagem em que há mais registros das cicatrizes devido às intensas chuvas de verão que ocorreram na região, poucos dias antes da data de captura da imagem. Os critérios para identificação das cicatrizes nas imagens foram ausência de vegetação, tonalidade, forma, posição na vertente e orientação. Para tal, utilizou-se o software ArcGis 10.1, o que possibilitou variações de escalas na extração das cicatrizes, desde 1:500 até 1:10.000, escalas de grande detalhamento.

A terceira etapa constituiu na avaliação da suscetibilidade a ocorrências de escorregamentos que foi feita por duas abordagens: Análise Integrada e Análise Paramétrica. Primeiramente foi realizada a análise integrada e depois a paramétrica, o que gerou dois mapas de suscetibilidade a escorregamento.

Na Análise Integrada foi realizada a compartimentação fisiográfica a partir de técnicas de fotointerpretação, segundo a metodologia proposta por Soares \& Fiori (1976), adaptada por Veneziani \& Anjos (1982) para imagens orbitais e aprimorada por Vedovello (2000) e Zaine (2011). 0 método proposto é dividido em três fases: fotoleitura, fotoanálise e fotointerpretação.

$\mathrm{Na}$ fotoleitura foi realizado reconhecimento nas imagens GeoEye dos elementos que compõem a paisagem relacionadas à drenagem $\mathrm{e}$ ao relevo. As imagens utilizadas foram as multiespectrais de Janeiro/2010 e de Maio/2010, além da pancromática de Julho/2010.
Na fotoanálise foi realizada a delimitação preliminar das unidades homólogas, segundo a disposição dos elementos de relevo e drenagem. Para tal, foram utilizados os critérios de análise, segundo Zaine (2011), representados pela análise das propriedades texturais do relevo e drenagem, análise das formas de relevo e das estruturas geológicas, além de análises complementares, baseadas na tonalidade/coloração. Com o auxílio do MDE, dos mapas hipsométrico, de declividade, de formas de vertentes, e dos dados geológicos e geomorfológicos da área, foi possível demarcar as unidades fisiográficas.

A fotointerpretação se baseou na assimilação dos resultados da fase de fotoanálise, através de métodos indutivos, dedutivos e comparativos, de forma a caracterizar as unidades compartimentadas, em função da relação dos objetos presentes na imagem. A partir dos critérios de análise, foram interpretadas as seguintes propriedades das unidades fisiográficas delimitadas; permeabilidade (intergranular e/ou fissural); resistência à erosão natural; composição e estrutura do material; grau de faturamento; ocorrência de solos derivados de rochas básicas/ácidas ou arenosas/argilosas; presença de água/umidade do solo; cobertura vegetal.

Na Análise Paramétrica, o mapa de suscetibilidade a escorregamento da área de estudo foi gerado por meio do cruzamento de diversos mapas temáticos, com a atribuição de pesos a cada um deles, bem como para cada classe dentro dos mapas. Os mapas temáticos utilizados nesse processo foram cinco: Mapa de Unidades Litológicas, Mapa de Unidades de Relevo, Mapa de Declividade, Mapa de Formas de Vertentes e o Mapa Hipsométrico.

0 procedimento foi realizado no software Arcgis 10.1 através da ferramenta Weighted Overlay. Foi empregado o Método de Processo de Análise Hierárquica (AHP), desenvolvido por Saaty (1992), na atribuição dos pesos ao longo do processo, de forma que os valores de prioridades estabelecidos ocorressem de forma organizada e menos subjetiva possível.

Para cada classe dos cinco mapas temáticos escolhidos, que compõe a análise paramétrica, foram atribuídos pesos que variam de 1 a 5 , 
onde o peso 1 corresponde à classe de mais baixa suscetibilidade de ocorrência dos processos de escorregamentos, e o peso 5 representa a mais alta suscetibilidade. 0 quadro 1 apresenta uma síntese dos critérios utilizados para a definição dos cinco pesos e que teve como base a pesquisa de Ross (1995).
Após a definição dos pesos de cada classe dos mapas temáticos foi realizada a ponderação dos cinco mapas entre si, para posterior

cruzamento dos mesmos, gerando o Mapa de Suscetibilidade a Escorregamento. A validação do mapa gerado foi feita através do Mapa de Inventário de Escorregamentos da área de estudo.

Quadro 1. Critérios utilizados para a definição dos pesos.

Chart 1. Criteria used to define weights.

\begin{tabular}{|cl|}
\hline PESOS & \multicolumn{1}{c|}{ Principais características para definição dos pesos } \\
\hline 1 & - Baixas declividades (inferiores a 5\%); \\
Suscetibilidade & - Relevo suave a plano; \\
Muito Baixa & - Composta por depósitos aluvionares. \\
\hline 2 & - Baixas declividades; \\
Baixa & - Relevo suave; \\
Suscetibilidade & - Baixa potencialidade de ocorrência dos processos do meio físico. \\
3 & - Declividades médias; \\
Média & - Média amplitude altimétrica; \\
Suscetibilidade & - Potencialidade de ocorrência de erosões lineares, escorregamentos e processos de \\
4 & rastejo. \\
Alta & - Declividades médias a altas; \\
Suscetibilidade & - Relevo dissecado; \\
- Presença de afloramentos rochosos superficiais; & - Presença de escorregamentos, rastejos, sulcos erosivos e rolamentos de blocos. \\
Suscetibilidade & - Altas declividades (acima de 30\%); \\
Muito Alta & - Relevo dissecado e escarpado; \\
& - Ocorrência de processos de escorregamentos e de quebra/rolamento de blocos. \\
\hline
\end{tabular}

Depois de gerados os mapas de suscetibilidade a escorregamento pelas duas abordagens, Integrada e Paramétrica, foi realizada uma comparação entre os resultados obtidos. Para tal, foram calculados os escorregamentos por quilômetro quadrado de cada classe de cada um dos mapas produzidos, o que gerou a relação cicatriz $/ \mathrm{km}^{2}$. A comparação quantitativa entre os mapas foi efetuada por meio da tabulação cruzada, utilizando-se a ferramenta Tabulate Area do ArcGis 10.1. Foi também realizada uma análise descritiva das diferenças entre os produtos obtidos.

\section{Resultados e discussões}

\subsection{Mapa de Suscetibilidade a Escorregamento - Compartimentação Fisiográfica}

O Mapa de Suscetibilidade a Escorregamento, elaborado a partir da compartimentação fisiográfica da área de estudo, é apresentado na figura 2. No processo de compartimentação fisiográfica foram delimitadas quatro unidades: Unidade I - Escarpas serranas; Unidade II - Domínio de colinas dissecadas, morrotes e morros baixos; Unidade III - Colinas isoladas; e Unidade IV - Planícies colúvio-aluvionar. É importante ressaltar que para a nomenclatura das unidades, adotou-se as unidades de relevo presentes na área de estudo. 


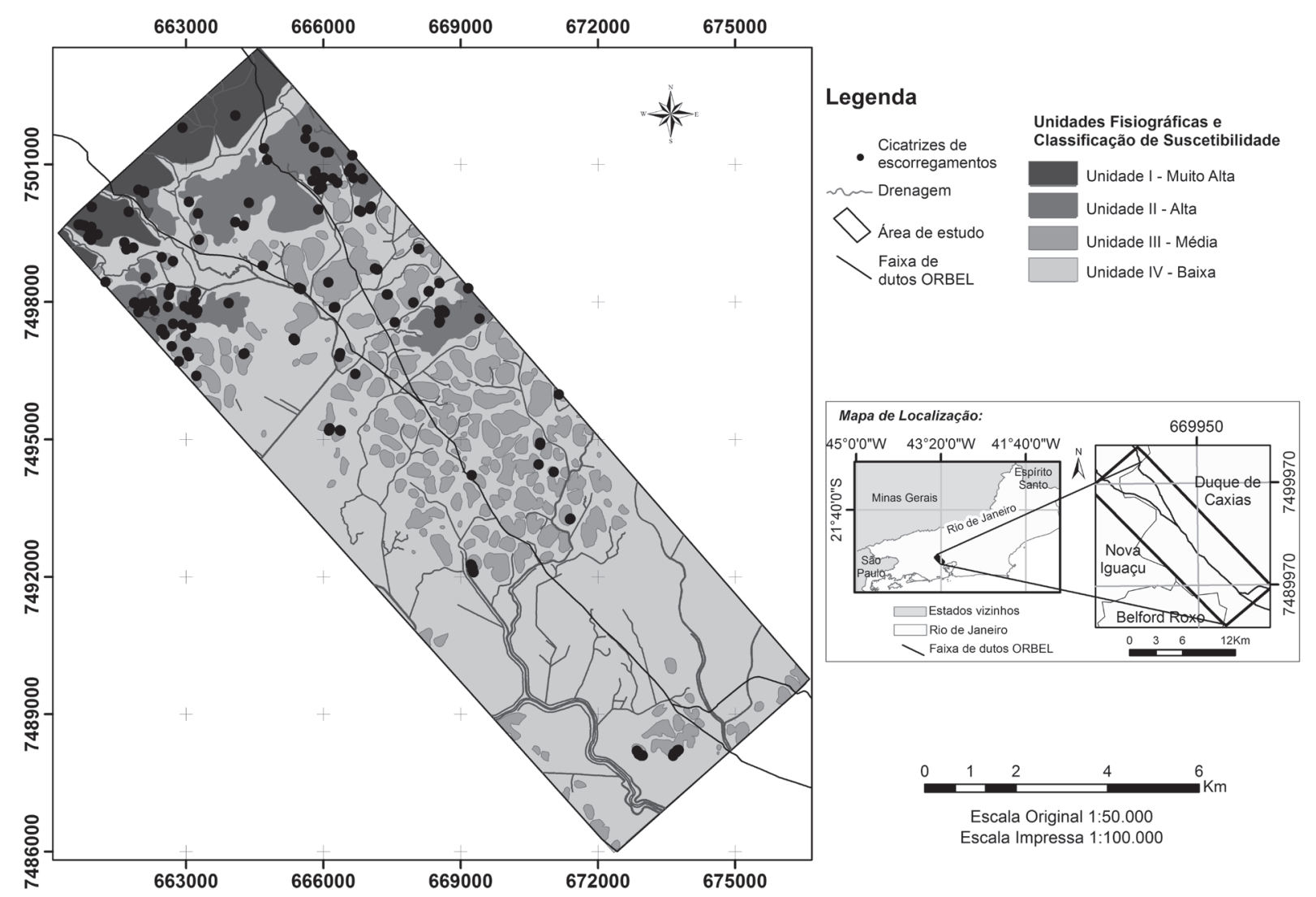

Figura 2. Mapa de Suscetibilidade a Escorregamento - Compartimentação Fisiográfica.

Figure 2. Landslide Susceptibility Map - Physiographic Compartmentation.

fica foram delimitadas quatro unidades: Unidade I - Escarpas serranas; Unidade II - Domínio de colinas dissecadas, morrotes e morros baixos; Unidade III - Colinas isoladas; e Unidade IV - Planícies colúvio-aluvionar. É importante ressaltar que para a nomenclatura das unidades, adotou-se as unidades de relevo presentes na área de estudo.

0 quadro 2 resume as análises e interpretações fotogeológicas realizadas para cada unidade fisiográfica, como proposto por Zaine (2011).

\subsubsection{Unidade I - Escarpas Serranas}

Esta unidade ocorre no extremo noroeste da área de estudo. A geologia predominante são granitos e granitoides da Unidade Serra dos Órgãos. A declividade é alta, em torno de $12 \%$ a $30 \%$, e em alguns locais passam de $30 \%$. As formas das vertentes são côncavas e retilíneas, as formas dos topos são angulosas e os vales fechados. É importante ressaltar que o sistema de relevo presente nesta unidade representa o final da faixa das escarpas serranas, que ocorrem bem mais ao norte do limite da área de estudo (Serra do Mar), por isso não apresenta os valores tão expressivos de altitudes, que se apresentam em torno dos $245 \mathrm{~m}$. As áreas presentes nesta unidade possuem baixa permeabilidade, a profundidade do topo rochoso de raso a subaflorante, a espessura de materiais inconsolidados delgada a não existente e são muito resistentes quanto ao grau de escavabilidade, conforme mostra o quadro 2 . 0 potencial à erosão linear é de médio a baixo e possui alto potencial a movimentos de massa e queda de blocos. Há registros de cicatrizes de escorregamentos nesta unidade, Mata Atlântica preservada, além de diversas culturas, como foi observado em trabalho de campo.

\subsubsection{Unidade II - Domínio de colinas dissecadas, morrotes e morros baixos}

Esta unidade se concentra na porção noroeste da área de estudo. A unidade geológica presente é a Unidade Serra dos Órgãos, composta majoritariamente por granitoides de granulação grossa. A unidade apresenta amplitudes médias a grandes, sendo o ponto mais alto de $325 \mathrm{~m}$, e declividades que variam de $12 \%$ a mais de $30 \%$. Os 
topos em sua maioria são angulosos, as formas das pelo quadro 2, mostram que as áreas possuem vertentes são côncavas e convexas e os vales fecha- média permeabilidade e espessura intermediária dos. As características geotécnicas dessa unidade, de materiais inconsolidados. A profundidade do

Quadro 2. Análise e interpretação fotogeológica aplicadas no estudo.

Chart 2. Photogeological analysis and interpretation applied in the study.

\begin{tabular}{|c|c|c|c|c|c|c|c|c|}
\hline Unidades & \multicolumn{6}{|c|}{ Fotointerpretação } & \multirow{2}{*}{\multicolumn{2}{|c|}{$\begin{array}{l}\text { Características da área } \\
\text { estudada }\end{array}$}} \\
\hline Classificacão de & \multicolumn{6}{|c|}{ Características geotécnicas } & & \\
\hline Suscetibilidade & $\begin{array}{l}\text { Permea- } \\
\text { bilidade }\end{array}$ & \multicolumn{2}{|c|}{$\begin{array}{l}\text { Profundidade } \\
\text { do topo } \\
\text { rochoso }\end{array}$} & $\begin{array}{c}\text { Grau de } \\
\text { escavabili- } \\
\text { dade }\end{array}$ & $\begin{array}{l}\text { Potencial } \\
\text { a erosão } \\
\text { linear }\end{array}$ & $\begin{array}{l}\text { Potencial a } \\
\text { movimentos } \\
\text { de massa }\end{array}$ & \multicolumn{2}{|c|}{$\begin{array}{c}\text { Processos geologicos/ } \\
\text { Uso e cobertura da } \\
\text { terra }\end{array}$} \\
\hline & Baixa & \multicolumn{2}{|c|}{$\begin{array}{l}\text { Raso a sub } \\
\text { aflorante }\end{array}$} & $\begin{array}{l}\text { Muito } \\
\text { resistente }\end{array}$ & $\begin{array}{l}\text { Médio a } \\
\text { baixo }\end{array}$ & Alto & \multicolumn{2}{|c|}{$\begin{array}{c}\text { Escorregamentos } \\
\text { Queda de blocos/ } \\
\text { Mata Atlântica } \\
\text { preservada. }\end{array}$} \\
\hline $\begin{array}{c}\text { II } \\
\text { Alta }\end{array}$ & Média & \multicolumn{2}{|c|}{ Intermediário } & $\begin{array}{c}\text { Resistência } \\
\text { Média }\end{array}$ & $\begin{array}{l}\text { Médio a } \\
\text { alto }\end{array}$ & Médio a alto & \multicolumn{2}{|c|}{$\begin{array}{c}\text { Escorregamentos } \\
\text { Erosão linear/ } \\
\text { Pastagens, fragmentos } \\
\text { de matas e agricultura. }\end{array}$} \\
\hline III & Média & \multicolumn{2}{|c|}{ Intermediário } & $\begin{array}{l}\text { Resistência } \\
\text { Média }\end{array}$ & Médio & Médio & \multicolumn{2}{|c|}{$\begin{array}{c}\text { Escorregamentos } \\
\text { Erosão linear/ } \\
\text { Pastagens e } \\
\text { fragmentos de matas. }\end{array}$} \\
\hline $\begin{array}{c}\text { IV } \\
\text { Baixa }\end{array}$ & Alta & \multicolumn{2}{|c|}{ Profundo } & $\begin{array}{l}\text { Pouco } \\
\text { resistente }\end{array}$ & $\begin{array}{l}\text { Baixo a } \\
\text { Médio }\end{array}$ & Baixo & \multicolumn{2}{|c|}{$\begin{array}{c}\text { Inundação, } \\
\text { assoreamento e } \\
\text { solapamento de } \\
\text { margens/ } \\
\text { Pastagens, fragmentos } \\
\text { de matas e agricultura. }\end{array}$} \\
\hline \multirow{3}{*}{$\begin{array}{c}\text { Unidades } \\
\text { Fisiográficas/ } \\
\text { Classificação de } \\
\text { Suscetibilidade }\end{array}$} & \multicolumn{2}{|c|}{ Subsuperfície } & \multicolumn{6}{|c|}{ Fotoanálise } \\
\hline & \multirow{2}{*}{\multicolumn{2}{|c|}{$\begin{array}{c}\text { Geologia/ } \\
\text { Geomorfologia }\end{array}$}} & $\begin{array}{r}f \\
\text { dens }\end{array}$ & $\begin{array}{l}\text { nálise da } \\
\text { dade textural }\end{array}$ & \multicolumn{4}{|c|}{ Análise das formas e características do relevo } \\
\hline & & & & $\begin{array}{l}\text { mentos de } \\
\text { enagem/ } \\
\text { mentos de } \\
\text { relevo }\end{array}$ & $\begin{array}{l}\text { Amplitud } \\
\text { Altimétric }\end{array}$ & $\begin{array}{c}\text { Declividad } \\
\text { e }\end{array}$ & $\begin{array}{l}\text { Forma } \\
\text { das } \\
\text { vertentes }\end{array}$ & $\begin{array}{l}\text { Forma } \\
\text { do vale }\end{array}$ \\
\hline & $\begin{array}{r}\text { Unidade } \\
\text { Alei } \\
\text { Escarpas }\end{array}$ & Tanto & & lta/Alta & $\begin{array}{l}\text { Média/ } \\
\text { Grande }\end{array}$ & Alta & $\begin{array}{l}\text { Côncava } \\
\text { Retilínea }\end{array}$ & Fechado \\
\hline $\begin{array}{c}\text { II } \\
\text { Alta }\end{array}$ & $\begin{array}{r}\text { Unidade } \\
\text { Órgã } \\
\text { Domínio d } \\
\text { dissec } \\
\text { morrotes } \\
\text { baix }\end{array}$ & $\begin{array}{l}\text { rra dos } \\
\text { s/ } \\
\text { Colinas } \\
\text { das, } \\
\text { morros } \\
\text { s. }\end{array}$ & & dia/Média & $\begin{array}{l}\text { Média/ } \\
\text { Grande }\end{array}$ & Alta & $\begin{array}{l}\text { Côncava } \\
\text { Convexa }\end{array}$ & Fechado \\
\hline III & $\begin{array}{r}\text { Unidade } \\
\text { Órgãos } \\
\text { Alei } \\
\text { Colinas i }\end{array}$ & $\begin{array}{l}\text { rra dos } \\
\text { Santo } \\
\text { / ladas }\end{array}$ & & dia/Média & Média & Média & $\begin{array}{l}\text { Convexa } \\
\text { Côncava }\end{array}$ & $\begin{array}{l}\text { Aberto } \\
\text { Fechado }\end{array}$ \\
\hline $\begin{array}{c}\text { IV } \\
\text { Baixa }\end{array}$ & $\begin{array}{r}\text { Depó } \\
\text { Colúvio-A } \\
\text { Planí } \\
\text { colúvio-a }\end{array}$ & $\begin{array}{l}\text { to } \\
\text { lvionar/ } \\
\text { les } \\
\text { lvionar }\end{array}$ & & dia/Baixa & Pequena & Baixa & - & Aberto \\
\hline
\end{tabular}


topo rochoso é intermediária e o grau de escavabilidade é médio. 0 potencial tanto à erosão linear quanto a movimentos de massa é médio. 0 trabalho de campo confirmou a ocorrência dos processos de movimentos de massa nessa unidade, além de verificar áreas de pastagens e agricultura.

\subsubsection{Unidade III - Colinas Isoladas}

Nesta unidade estão presentes os granitoides das Unidades Serra dos Órgãos e Santo Aleixo. 0 relevo é de colinas isoladas com amplitudes pequenas de 45 a $85 \mathrm{~m}$. Apresenta médias declividades, de 5 a 12\%, e média densidade de drenagem. As formas das vertentes são em sua maioria convexas, mas apresenta em alguns locais as formas côncavas. Como mostra o quadro 2, esta unidade apresenta média permeabilidade, com profundidade intermediária do topo rochoso e intermediária espessura de materiais inconsolidados, além de médio grau de escavabilidade. Apresenta médio potencial à erosão linear e a movimentos gravitacionais de massa. Dados de campo confirmam que nesta unidade predomina o uso de pastagens e apresenta feições erosivas, inclusive registros de feições próximas ao duto ORBEL, além de sulcos em encostas.

\subsubsection{Unidade IV - Planícies Colúvio-aluvionar}

Esta unidade apresentam os Depósitos Aluvionares e estende-se por toda área, com concentração maior na sua porção centro-sul. As elevações não ultrapassam os $45 \mathrm{~m}$. Possui pequenas amplitudes, baixas declividades (até 5\%) e os vales abertos. De acordo com o Quadro 3, em relação às características geotécnicas desta unidade, as áreas apresentam alta permeabilidade, baixo grau de escavabilidade e possuem espessos materiais inconsolidados. 0 potencial à erosão linear é de baixo a médio e possui baixo potencial a movimentos de massa. 0 registro mostra que nessas áreas ocorrem inundações, assoreamentos e podem ocorrer solapamentos das margens dos rios, e que são áreas em que há o predomínio de pastagens e agricultura.

Tabela 1. Matriz AHP de comparação pareada dos mapas temáticos.

Table 1. AHP matrix of matched thematic maps.

\begin{tabular}{c|c|c|c|c|c}
\hline & Hipsométrico & $\begin{array}{c}\text { Unidades } \\
\text { Litológicas }\end{array}$ & $\begin{array}{c}\text { Unidades de } \\
\text { Relevo }\end{array}$ & Declividade & $\begin{array}{c}\text { Forma de } \\
\text { Vertentes }\end{array}$ \\
\hline Hipsométrico & 1 & $1 / 2$ & $1 / 5$ & $1 / 7$ & $1 / 3$ \\
\hline $\begin{array}{c}\text { Unidades } \\
\text { Litológicas }\end{array}$ & $2 / 1$ & 1 & $1 / 3$ & $1 / 5$ & $1 / 3$ \\
\hline $\begin{array}{c}\text { Unidades de } \\
\text { Relevo }\end{array}$ & $5 / 1$ & $3 / 1$ & 1 & $1 / 3$ & $3 / 1$ \\
\hline Declividade & $7 / 1$ & $5 / 1$ & $3 / 1$ & 1 & $3 / 1$ \\
\hline $\begin{array}{c}\text { Forma de } \\
\text { Vertentes }\end{array}$ & $3 / 1$ & $3 / 1$ & $1 / 3$ & $1 / 3$ & 1 \\
\hline SOMA & 18 & $25 / 2$ & $73 / 15$ & $211 / 105$ & $23 / 3$ \\
\hline
\end{tabular}

3.2 Mapa de Suscetibilidade a Escorregamento Método AHP

Conforme o método desenvolvido por Saaty (1992) para obtenção dos pesos que posteriormente serão atribuídos aos cinco mapas temáticos, foram realizados os cálculos apresentados nas seguintes tabelas: a tabela 1 apresenta a matriz de comparação pareada dos mapas, a tabela 2 mostra a normalização da matriz AHP e o autovetor de cada atributo julgado, e a tabela 3 exibe a análise de erro do método.

Dessa forma, a declividade aparece como fator mais importante, com ordem de prioridade de $45,86 \%$. Em seguida, o relevo, representado no Mapa de Unidades de Relevo, com ordem de importância de 25,61\%, seguido pelas Formas de Vertentes com ordem de 15,43\%. Por último, aparecem as Unidades Litológicas, com 8,05\%, e a Hipsometria com 5,02\%. De acordo com o método de Saaty (1992), os valores obtidos são consistentes, pois o valor resultante de 5,83\% da Razão 
Tabela 2. Matriz normalizada e valores do autovetor.

Table 2. Normalized matrix and eigenvector values.

\begin{tabular}{c|c|c|c|c|c|c}
\hline & Hipsométrico & $\begin{array}{c}\text { Unidades } \\
\text { Litológicas }\end{array}$ & $\begin{array}{c}\text { Unidades de } \\
\text { Relevo }\end{array}$ & Declividade & $\begin{array}{c}\text { Forma de } \\
\text { Vertentes }\end{array}$ & Autovetor \\
\hline Hipsométrico & $1 / 18$ & $1 / 25$ & $3 / 73$ & $15 / 211$ & $1 / 23$ & 0,0502 \\
\hline $\begin{array}{c}\text { Unidades } \\
\text { Litológicas }\end{array}$ & $2 / 18$ & $2 / 25$ & $5 / 73$ & $21 / 211$ & $1 / 23$ & 0,0805 \\
\hline $\begin{array}{c}\text { Unidades de } \\
\text { Relevo }\end{array}$ & $5 / 18$ & $6 / 25$ & $15 / 73$ & $35 / 211$ & $9 / 23$ & 0,2561 \\
\hline $\begin{array}{c}\text { Declividade } \\
\text { Forma de } \\
\text { Vertentes }\end{array}$ & $7 / 18$ & $10 / 25$ & $45 / 73$ & $105 / 211$ & $9 / 23$ & 0,4586 \\
\hline SOMA & 1 & $6 / 25$ & $5 / 73$ & $35 / 211$ & $3 / 23$ & 0,1543 \\
\hline
\end{tabular}

de Consistência (RC) é menor que 10\%, o que valida o método.

O Mapa de Suscetibilidade a Escorregamento, elaborado por meio do Método AHP (Análise Paramétrica), é apresentado na figura 3.

Tabela 3. Análise de Erro.

Table 3. Error Analysis.

\begin{tabular}{c|c}
\hline Cálculos & Valores \\
\hline$\lambda$ max & 5,2614 \\
\hline IC & 0,0653 \\
\hline ICR & 1,12 \\
\hline \multirow{2}{*}{ RC } & 0,0583 \\
& $5,83 \%$ \\
\hline
\end{tabular}

As tabelas 4 e 5 mostram a relação cicatriz por quilômetro quadrado das classes de cada um dos dois mapas de suscetibilidade a escorregamento. A figura 4 mostra um gráfico que compara as relações cicatriz $/ \mathrm{km}^{2}$.

A partir dessa relação cicatriz $/ \mathrm{km}^{2}$, observou-se que no Mapa de Suscetibilidade a Escorregamento - Compartimentação Fisiográfica, a relação é maior na Unidade II, considerada de alta suscetibilidade a escorregamento. No Mapa de Suscetibilidade a Escorregamento - Método AHP, essa relação é maior na classe muito alta. Entretanto, a área de abrangência da classe muito alta (método AHP) é de 1,82 $\mathrm{km}^{2}$, enquanto a Unidade
I - muito alta possui $5,45 \mathrm{~km}^{2}$.

Essa diferença nos valores da relação cicatriz $/ \mathrm{km}^{2}$, deve-se ao fato do Método AHP possuir maior precisão na delimitação das classes de suscetibilidade, pois na atribuição de pesos o fator mais importante foi o Mapa de Declividade, que apresenta contorno bastante detalhado das classes, com ordem de prioridade de $45,86 \%$. Já na definição das unidades fisiográficas do Mapa de Suscetibilidade a Escorregamento - Compartimentação Fisiográfica, a delimitação foi realizada por fotointerpretação da imagem GeoEye, o que compreende uma visão mais abrangente e subjetiva, pois depende da experiência do fotointérprete.

A tabela 6 apresenta os valores, em quilômetros quadrados, obtidos pela tabulação cruzada realizada entre as classes dos mapas de suscetibilidade a escorregamento da compartimentação fisiográfica e do método AHP. Estes valores demonstram o quanto de uma classe de um mapa está presente nas classes do mapa gerado por outro método, assim fazendo uma comparação direta e quantitativa entre as classes de cada mapa.

As divergências observadas na tabulação cruzada entre os mapas produzidos pelos dois métodos são decorrentes das diferenças dos limites traçados entre as classes em cada mapa. 0 Mapa de Suscetibilidade a Escorregamento - Compartimentação Fisiográfica, elaborado a partir dos conceitos propostos por Soares \& Fiori (1976) e Vedovello (2000), considera regiões inteiras como uma única classe, como no caso da porção das escarpas serranas, classificada como classe Muito Alta, e das colinas isoladas que são classificadas 
Tabela 4. Relação de cicatrizes de escorregamentos por $\mathrm{km}^{2}$ em cada unidade fisiográfica. Table 4. Relationship of scars of landslides per $\mathrm{km}^{2}$ in each physiographic unit.

\begin{tabular}{c|c|c|c}
\hline Unidades Fisiográficas & Área $\left(\mathbf{k m}^{2}\right)$ & $\begin{array}{c}\text { Cicatrizes } \\
\text { escorregamentos }\end{array}$ & $\begin{array}{c}\text { Relação } \\
\text { cicatriz/km }\end{array}$ \\
\hline Unidade I - Muito Alta & 5,45 & 17 & 3,12 \\
\hline Unidade II - Alta & 9,73 & 81 & 8,33 \\
\hline Unidade III - Média & 17,01 & 67 & 3,94 \\
\hline Unidade IV - Baixa & 74,29 & 0 & - \\
\hline
\end{tabular}

Tabela 5. Relação de cicatrizes de escorregamentos por $\mathrm{km}^{2}$ em cada classe (AHP). Table 5. Relationship of scars of landslides per $\mathrm{km}^{2}$ in each class (AHP).

\begin{tabular}{c|c|c|c}
\hline $\begin{array}{c}\text { Classes de Suscetibilidade } \\
\text { (AHP) }\end{array}$ & Área $\left(\mathrm{km}^{2}\right)$ & $\begin{array}{c}\text { Cicatrizes } \\
\text { escorregamentos }\end{array}$ & $\begin{array}{c}\text { Relação } \\
\text { cicatriz/km }\end{array}$ \\
\hline Muito Alta & 1,82 & 31 & 17,03 \\
\hline Alta & 20,64 & 108 & 5,23 \\
\hline Média & 9,02 & 26 & 2,88 \\
\hline Baixa & 74,98 & 0 & - \\
\hline
\end{tabular}

\section{Relação cicatriz/ $\mathrm{Km}^{2}$}

\section{Unidades Fisiográficas M Método AHP}

\section{7,03}

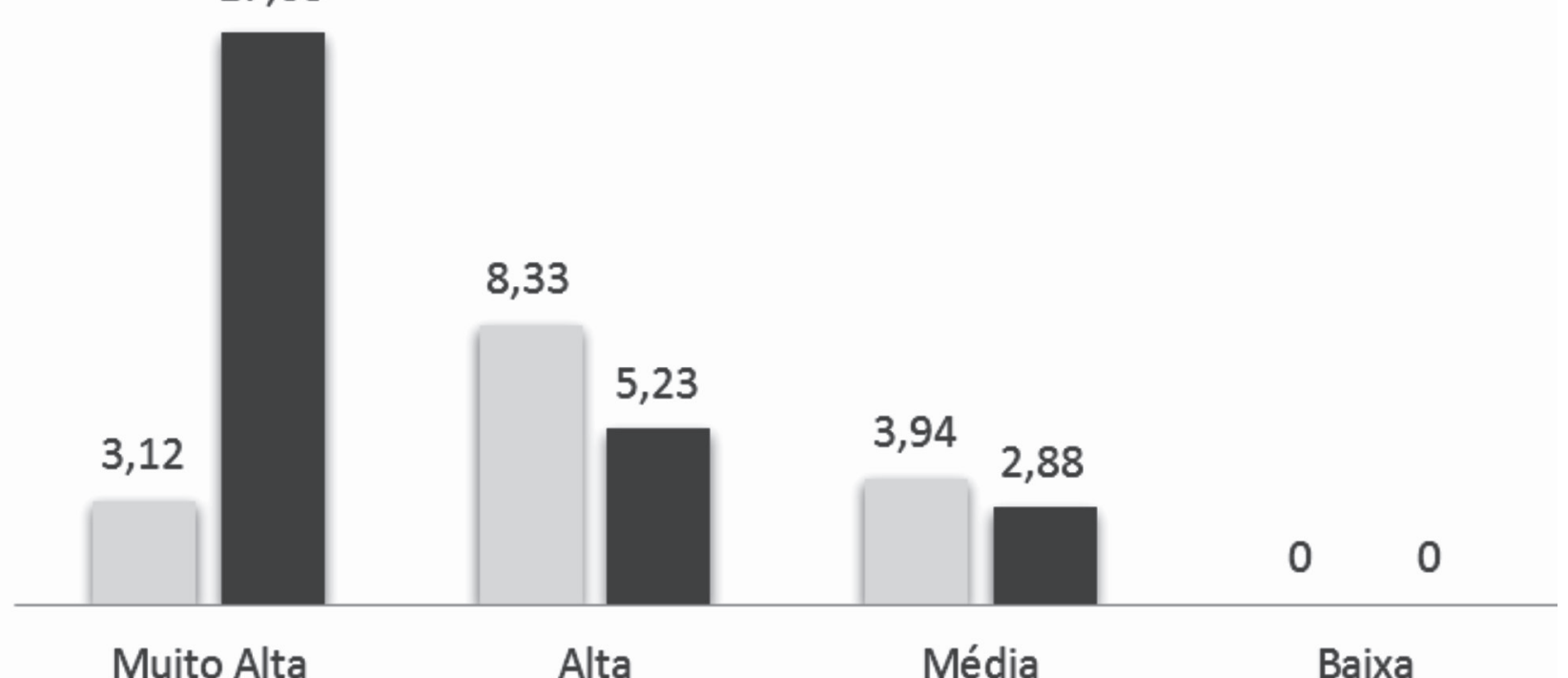

Figura 4. Gráfico da relação cicatriz $/ \mathrm{km}^{2}$ das classes dos dois mapas de suscetibilidade.

Figure 4. Scar $/ \mathrm{km}^{2}$ graph of the two susceptibility maps classes.

como classe Média. No Mapa de Suscetibilidade a

Escorregamento - Método AHP, estas regiões são fracionadas em duas ou mais classes, pois este mapa incorpora na sua composição a declividade, que é bastante detalhada. Este detalhamento desempenha um importante papel na configuração dos contornos das classes do mapa de suscetibilidade por este método, uma vez que o Mapa de
Declividade aparece como fator mais importante da análise, com ordem de prioridade de 45,86\%. Além disso, é importante ressaltar que o mapa de declividade foi produzido a partir de cartas topográficas em escalas de 1:10.000, condição de especial detalhe e nem sempre disponíveis para todas as regiões do Brasil. 
Em decorrência do maior detalhamento, principalmente na área das vertentes, tem-se que 84,24\% das 165 cicatrizes mapeadas estão localizadas nas classes de Muito Alta e Alta suscetibilidade no mapa gerado na análise paramétrica, pelo método AHP, enquanto 59,39\% se situam nestas mesmas classes no mapa gerado na análise integrada, por compartimentação fisiográfica. Observa-se, desta forma, um resultado aparentemente mais coerente no mapa produzido pela Abordagem Paramétrica.

Tabela 6. Valores em quilômetros quadrados resultantes da tabulação cruzada entre os mapas de suscetibilidade a escorregamento.

Table 6. Values in square kilometers resulting from cross tabulation between susceptibility maps to landslide.

\begin{tabular}{c|c|c|c|c}
\cline { 2 - 5 } & \multicolumn{4}{c}{ Classes de Suscetibilidade AHP } \\
\cline { 2 - 5 } UISIOFADES & Classe Muito Alta & Classe Alta & Classe Média & Classe Baixa \\
\hline Unidade I Muito Alta & 0,5374 & 3,2006 & 0,5402 & 1,1673 \\
\hline $\begin{array}{c}\text { Unidade II } \\
\text { Alta }\end{array}$ & 1,2737 & 7,6392 & 0,6664 & 0,1441 \\
\hline $\begin{array}{c}\text { Unidade III } \\
\text { Média }\end{array}$ & 0 & 8,9991 & 7,5188 & 0,4892 \\
\hline $\begin{array}{c}\text { Unidade IV } \\
\text { Baixa }\end{array}$ & 0,0084 & 0,7438 & 0,2978 & 72,9855 \\
\hline
\end{tabular}

\section{Conclusões}

Conclui-se que a utilização de imagens orbitais de alta resolução espacial contribui na identificação dos elementos texturais do relevo, auxiliando a delimitação das diferentes unidades fisiográficas, como já observado por Veneziani \& Anjos (1982) e, principalmente também na extração de cicatrizes de escorregamentos. Estas feições são mais claramente identificadas e corretamente posicionadas nas vertentes, o que propicia uma melhor validação das classes de suscetibilidade dos mapas gerados, principalmente quando se utiliza a análise AHP que, no caso da área de estudo, foi ancorada num detalhado mapa de declividade. Observou-se que os escorregamentos registrados ocorrem próximos à faixa de dutos ORBEL, o que mostra a importância deste tipo de análise, pois, por meio de seu subsídio, as áreas com maior suscetibilidade à ocorrência de processos de movimentos de massa podem ser constantemente monitoradas, para evitar potenciais acidentes no duto decorrentes destes eventos.

Comparando-se as duas formas de obtenção da suscetibilidade a escorregamento na área de estudo, a integrada com a paramétrica, conclui-se que a Análise Paramétrica, apoiada no Método AHP de Saaty (1992), possibilitou um mapa mais detalhado e aparentemente mais consistente, com 84,24\% das cicatrizes mapeadas nas classes de Muito Alta e Alta suscetibilidade, contra 59,39\% das cicatrizes nestas mesmas classes, no mapa gerado pela Análise Integrada. No caso específico da área de estudo, a utilização de cartas topográficas em escala de 1:10.000, conduziu à elaboração de um detalhado mapa de declividade, o que nem sempre é possível. Deste detalhamento decorreu um mapa de suscetibilidade onde as classes são fragmentadas em pequenos polígonos, que representam as variações locais e mais precisas da declividade ao longo das encostas. Este detalhamento, associado à utilização das imagens de alta resolução espacial, que propiciou a localização também precisa das cicatrizes em cada classe de declividade, conduziu a uma maior confiabilidade no processo de validação, com possibilidades de quantificação. 0 conjunto de condições propiciou a maior precisão do produto gerado por esta abordagem, em comparação à Análise Integrada, que considera maiores regiões como unidade de análise.

Na Abordagem Paramétrica, utilizando o método AHP, o cruzamento dos mapas exige que todos estejam na mesma escala, ou em escalas próximas, e ainda compatíveis com o detalhamen- 
to necessário ao estudo do processo do meio físico abordado, condição muitas vezes difícil de ser atendida em várias regiões do território brasileiro, onde há carência de mapas temáticos em grandes escalas. Tal condição assume relevância no caso de faixas de dutos, que são obras lineares e, muitas vezes de grande extensão, que podem atravessar vários estados, com disponibilidades distintas de mapeamento e escalas, o que dificulta a análise de toda a faixa com a mesma metodologia.

$\mathrm{Na}$ Abordagem Integrada não há necessidade que os mapas possuam a mesma escala, pois é utilizada apenas a imagem orbital ou fotografia aérea como base e o levantamento de informações geomorfológicas e geológicas da área em questão para conhecimento do fotointérprete, conforme os trabalhos de Soares \& Fiori (1976), Vedovello (2000) e Zaine (2011). Estas informações alimentam o banco de dados dos compartimentos e são checadas em campo. Neste caso, a análise será mais subjetiva, pois depende do conhecimento e experiência de cada fotointérprete. Esta subjetividade é reduzida no Método AHP, utilizado na Análise Paramétrica, pois as avaliações estatísticas eliminam julgamentos inconsistentes.

Embora tenham sido constatadas discrepâncias entre os resultados obtidos nos dois métodos, ressalta-se que a Análise Integrada, a princípio mais generalista, consiste em uma interessante alternativa para regiões carentes de mapas temáticos em escalas compatíveis com análises mais detalhadas, como é o caso de análise de suscetibilidade a escorregamentos. No caso do presente trabalho, a utilização dos mapas existentes, em escalas inicialmente inapropriadas a este tipo de análise, só foi possível após criteriosa adequação de escalas, que consistiu em detalhamento dos contatos dos mapas geológico e geomorfológico por meio de fotointerpretação. Este detalhamento, por sua vez, foi facilitado pelo fato da área de estudo apresentar fortes contrastes geomorfológicos, por sua vez com grande associação com as litologias existentes, situação nem sempre encontrada em todas as áreas, o que pode dificultar a adequação de escalas por meio da fotointerpretação e comprometer fortemente os resultados da Análise Paramétrica, que passam a não ser confiáveis.
Uma forma de se diminuir a diferença entre os resultados dos mapas obtidos pelas duas abordagens, seria buscar um maior detalhamento na fotointerpretação das imagens orbitais, separando as regiões de maior declividade das encostas. Poderiam ser criados subcompartimentos de maior declividade, como no caso, por exemplo, do compartimento Domínio de colinas dissecadas, morrotes e morros baixos, que apresenta declividades que variam de $12 \%$ a mais de $30 \%$ e foi considerada no mapa gerado pela Análise Integrada como sendo unicamente de alta suscetibilidade.

Para faixa de dutos, que abrangem grandes extensões, a Análise Integrada constitui-se em interessante opção que pode ser elaborada com maior detalhe, com a utilização de produtos de sensoriamento remoto de alta resolução espacial e modelos digitais de elevação, sem a necessidade de mapas temáticos em escalas compatíveis e detalhadas. A utilização das duas abordagens, de forma complementar, pode ser uma interessante alternativa, onde a Análise Paramétrica seja utilizada em locais indicados como de alta suscetibilidade na Análise Integrada.

Agradecimentos. Os autores agradecem a CAPES pela bolsa de estudo concedida, e ao CENPES Petrobras pelo fornecimento de informações e auxílio financeiro.

\section{Referências}

Aguiar, R.L. 1997. Zoneamento geotécnico geral do Distrito Federal: procedimentos metodológicos e sua inserção na gestão ambiental. São Carlos. Tese de Doutorado, Programa de Pós-graduação em Geotecnia, Escola de Engenharia de São Carlos, Universidade de São Paulo.

Ahmed, B. 2015. Landslide susceptibility mapping using multi-criteria evaluation techniques in Chittagong Metropolitan Area, Bangladesh. Landslide, 12: 1077-1095.

Akgun, A. \& Türk, N. 2010. Landslide susceptibility mapping for Ayvalik (Western Turkey) and its vicinity by multicriteria decision analysis. Environmental Earth Sciences, 61: 595-611.

Aleotti, P. \& Chowdhury, R. 1999. Landslide hazard assessment: summary review and new perspectives. Bulletin of International Association 
of Engineering Geology and Environmental, 58: 21-44.

Amaral, A.M.C. 2014. Zoneamento geoambiental do município de Casa Branca (SP). Rio Claro, 141p. Dissertação de Mestrado, Programa de Pós-graduação em Geociências e Meio Ambiente, Instituto de Geociências e Ciências Exatas, Universidade Estadual Paulista.

Araujo, P.C. 2004. Estudo da suscetibilidade a escorregamentos em S. Sebastião, SP: uma abordagem probabilística. Rio Claro, 190p. Tese de Doutorado, Programa de Pós-graduação em Geociências e Meio Ambiente, Instituto de Geociências e Ciências Exatas, Universidade Estadual Paulista.

Ayalew, L., Yamagishi, H. \& Ugawa, N. 2004. Landslide susceptibility mapping using GIS-based weighted linear combination, the case in Tsugawa area of Agano River, Niigata Prefecture, Japan. Landslides, 1: 73-81.

Barredo, J., Benavides, A., Hervas, J. \& van Westen, C.J. 2000. Comparing heuristic landslide hazard assessment techniques using GIS in the Tirajana basin, Gran Canária Island, Spain. ITC Journal, 2: 9-23.

Bennett, M.R. \& Doyle, P. 1997. Environmental Geology. Geology and the human environment. Chichester, John Wiley and Sons. 501 p.

Buringh, P. 1960. The applications of aerial photographs in soil surveys. In: American Society Photogrammetry. Manual of photographic interpretation. Washington. p. 633-666.

Christian, C. S., \& Stewart, G. A. 1953. General report on survey of Katherine-Darwin region, 1946. Melbourne, CSIRO. Australian Land Reasearch Series, n.1.

Christian, C.S. 1958. The concept of land units and land systems. In: Pacific Science Congress, 9., 1958. Proceedings..., p. 74-81.

Christian, C.S. \& Stewart, G.A. 1964. Methodology of integrated surveys. In: Conference on Principles and Methods of Integrating Aerial Studies of Natural Resources for Potential Development, 1964, Toulouse. Proceedings... Toulouse, UNESCO. p. 233-277.

Collares, E.G. 1994. Mapeamento geotécnico da quadrícula de Bragança Paulista (escala 1:50.000): ênfase nos materiais inconsolidados.
São Carlos, 2v. Dissertação de Mestrado, Programa de Pós-graduação em Geotecnia, Escola de Engenharia de São Carlos, Universidade de São Paulo.

CPRM. Companhia de Pesquisa de Recursos Minerais. 2000. Projeto Rio de Janeiro. Brasília, CPRM (Relatório Técnico).

Crepani, E., Medeiros, J.S., Hernandez Filho, P., Florenzano, T.G., Duarte, V. \& Barbosa, C.C.F. 2001. Sensoriamento remoto e geoprocessamento aplicados ao zoneamento ecológico-econômico e ao ordenamento territorial. São José dos Campos: Inpe (INPE-8454- RPQ/722).

De Biase, M. 1970. Cartas de Declividade: Confecção e Utilização. Geomorfologia, 21: 8-12.

Diniz, N.C. 2012. Cartografia geotécnica por classificação de unidades de terreno e avaliação de suscetibilidade e aptidão. Revista Brasileira de Geologia de Engenharia e Ambiental, 2: 29-77.

ESRI. Environmental Systems Research Institute. 2010. ArcGIS Desktop: Release 10.1. Redlands, CA.

Feizizadeh, B. \& Blaschke, T. 2013. GIS-multicriteria decision analysis for landslide susceptibility mapping: comparing three methods for the Urmia lake basin, Iran. Natural Harzards, 65: 2105-2128.

Fernandes, N.F., Guimarães, R.F., Gomes, R.A.T., Vieira, B.C., Montgomery, D.R. \& Greenberg, H. 2001. Condicionantes geomorfológicos dos deslizamentos nas encostas: avaliação de metodologias e aplicação de modelo de previsão de áreas susceptíveis. Revista Brasileira de Geomorfologia, 2: 51-71.

Ferreira, M.V., Riedel, P.S., Lopes, E.S.S. \& Merino, E.R. 2008. Comparação entre diferentes critérios para elaboração de mapas de suscetibilidade aos escorregamentos: exemplo do município de Cubatão, Serra do Mar Paulista. Revista Brasileira de Cartografia, 60: 385-400.

Gorsevski, P.V., Jankowski, P. \& Gessley, P.E. 2006. A heuristic approach for mapping landslide harzard by integrating fuzzy logic with analytic hierarchy process. Control and Cybernetics, 35: 121-146.

Grant, K. 1970. Terrain Evaluation. A logical extension of engineering geology. In: International Congress of the IAEG, 1., 1970, Paris. Proceed- 
ings... Paris, IAEG, v. 2, p. 971-980.

Grant, K. 1975a. The PUCE Programme for terrain evaluation for engineering purposes I: principles. Australia, Division of Applied Geomechanics. Commonwealth Scientific and Industrial Research Organization (Technical Paper, 15).

Grant, K. 1975b. The PUCE Programme for terrain evaluation for engineering purposes; II: procedures for terrain classification. Austrália, Division of Applied Geomatematics. Commonwealth Scientific and Industrial Research Organization (Technical Paper, 19).

Grant, K. \& Finlayson, A. 1978. The application of terrain analysis to urban regional planning. In: International Congress of the IAEG, 3., 1978, Madrid. Proceedings... Madrid, IAEG. p. 79-91.

Guidicini, G. \& Nieble, C.M. 1984. Estabilidade de taludes naturais e de escavação. 2 $2^{\underline{a}}$ Edição. São Paulo, Edgard Blücher, 194p.

IPT. Instituto de Pesquisas Tecnológicas do Estado de São Paulo. 1988. Programa Serra do Mar: Estudo geotécnico dos principais mecanismos de instabilização na Serra do Mar. São Paulo, IPT (Relatório 25.957).

Komac, M. 2006. A landslide susceptibility model using Analytical Hierarchy Process method and multivariate statistics in perialpine Slovenia. Geomorphology, 74: 17-28.

Lee, S. 2005. Application of logistic regression model and its validation for landslide susceptibility mapping using GIS and remote sensing data. Journal of Remote Sensing, 26: 1477-1491.

Lepsch, I.F., Bellinazzi, J.R., Bertolini, D. \& Espíndola, C.R. 1991. Manual para levantamento utilitário do meio físico e classificação de terras no sistema de capacidade de uso. Sociedade Brasileira de Ciência do Solo, Campinas, 175p.

Lollo, J.A. de 1996. O uso da técnica de avaliação do terreno no processo de elaboração do mapeamento geotécnico: sistematização e aplicação na quadrícula Campinas. São Carlos, 2v. Tese de Doutorado, Programa de Pós-Graduação em Geotecnia, Escola de Engenharia de São Carlos, Universidade de São Paulo.

Lopes, E.S.S., Riedel, P.S., Bentz, C.M. \& Ferreira, M.V. 2007. Calibração e validação do índice de estabilidade de encostas com inventário de escorregamentos naturais na Bacia do Rio da
Onça na Região da Serra de Cubatão, SP. Geociências, 26: 83-95.

Mitchell, C.W. 1973. Terrain Evaluation. London, Longman. $459 \mathrm{p}$.

NIMA. Núcleo Interdisciplinar de Meio Ambiente; PETROBRAS; Prefeitura Municipal de Duque de Caxias. 2009. Educação Ambiental: formação de valores ético-ambientais para o exercício da cidadania no Município de Duque de Caxias. PUCRio. Disponível em: <http://www.nima.puc-rio. br>. Acesso em: 6 mai. 2014.

NIMA. Núcleo Interdisciplinar de Meio Ambiente; PETROBRAS; Prefeitura Municipal de Nova Iguaçu. 2010. Educação Ambiental: formação de valores ético-ambientais para o exercício da cidadania no Município de Nova Iguaçu. PUC-Rio. Disponível em: <http://www.nima.puc-rio.br>. Acesso em: 6 mai. 2014.

Ross, J.L.S. 1995. Análises e sínteses na abordagem geográfica da pesquisa para o planejamento ambiental. Revista do Departamento de Geografia, 9: 65-75.

RSI. Research Systems Inc. 2009. The Environment for Visualizing Images. Boulder, CO, USA.

Saaty, T.L. 1992 Multicriteria Decision Making The Analytical Hierarchy Process. RWS Publications.

Silveira, H.L.F., Vettorazzi, C.A. \& Valente, R. A. 2014. Avaliação multicriterial no mapeamento da suscetibilidade de deslizamentos de terra. Árvore, 38: 973-98

Soares, P.C. \& Fiori, A.P. 1976. Lógica e Sistemática na Análise e Interpretação de Fotografias Aéreas em Geologia. Notícia Geomorfológica, 32: 71104.

Souza, N.C.D.C. 1992. Mapeamento geotécnico regional da Folha de Aguaí: com base na compartimentação por formas de relevo e perfis típicos de alteração. São Carlos, 2v. Dissertação de Mestrado, Programa de Pós-Graduação em Geotecnia, Escola de Engenharia de São Carlos. Universidade de São Paulo.

Tominaga, L.K. 2007. Aplicação de metodologias de análise de risco a escorregamentos. Aplicação de um ensaio em Ubatuba, SP. São Paulo, 220p. Tese de Doutorado, Programa de Pós Graduação em Geografia Física, Faculdade de Ciências, Letras e Ciências Humanas, Universidade de São Paulo. 
Valeriano, M.M. 2008. Topodata: guia para utilização de dados geomorfológicos locais. São José dos Campos, INPE, 75p (Relatório INPE15318-RQP/818).

Vedovello, R. 2000. Zoneamentos geotécnicos aplicados à gestão ambiental, a partir de unidades básicas de compartimentação - UBCs. Rio Claro, 154p. Tese de Doutorado, Programa de Pós-graduação em Geociências e Meio Ambiente, Instituto de Geociências e Ciências Exatas, Universidade Estadual Paulista.

Veneziani, P. \& Anjos, C.E. 1982. Metodologia de interpretação de dados de sensoriamento remoto e aplicações em geologia. São José dos Campos, INPE, 54p (INPE-2227-MD/014).

Verstappen, H.Th. 1983. Applied geomorphology. Amsterdam: Elsevier. 437p.

Verstappen, H.Th \& Zuidam, R.A.V. 1975. The ITC system of geomorphological mapping. s.l. ITC VII-2 (Textbook).

Wolle, C.M. \& Carvalho, C.S. 1989. Deslizamentos em encostas na Serra do Mar - Brasil. Solos e Rochas, 12: 27-36.

Yalcin, A. 2008. GIS-based landslide susceptibility mapping using analytical hierarchy process and bivariate statistics in Ardesen (Turkey): Comparisons of results and confirmations. Catena, 72: 1-12.

Zaine, J.E. 2011. Método de fotogeologia aplicado a estudos geológico-geotécnicos: ensaio em Poços de Caldas, MG. Rio Claro, 104p. Tese de Livre-docência. Instituto de Geociências e Ciências Exatas, Universidade Estadual Paulista.

Zuquette, L.V. \& Pejon, O. 1996. Carta de zonea- mento geotécnico geral da região de Franca (SP), utilizando os critérios de landforms. In: Simpósio Brasileiro de Cartografia Geotécnica, 2., 1996, São Carlos. Anais... São Carlos, ABGE. 